\title{
Mucolipidosis type III gamma
}

INSERM

\section{Source}

INSERM. (1999). Orphanet: an online rare disease and orphan drug data base.

Mucolipidosis type III gamma. ORPHA:423470

Mucolipidosis type III gamma (ML 3 gamma) is a very rare lysosomal disease, that has most often been observed in the Middle East, characterized by a progressive slowing of the growth rate in early childhood; stiffness and pain in shoulders, hips, and finger joints; a gradual, mild coarsening of facial features; and by a slower progression, milder clinical course and longer life expectancy than that seen in mucolipidosis type II and mucolipidosis type III alpha/beta. Cognitive function is normal or only slightly impaired and retinitis pigmentosa has been reported in a few patients. Many survive into early adulthood, but ultimately succumb to cardiorespiratory insufficiency. 